\section{Sammlung Kleiner Schriften zur Neurosenlehre (Collection of Short Studies on the Neuroses). By Professor Freud. Leipzig and Vienna: Deuticke, 1906. Pp. 234, 8vo.}

Professor Freud's elaborate and painstaking efforts to elucidate the mechanism of hysteria and of various allied neurotic conditions, notwithstanding the opposition with which they have sometimes been met, have aroused a growing interest, and he has been induced to bring together the various studies (three of them in French) which he has published on this subject during the past fourteen years. The volume forms an admirable introduction to Freud's work. We are enabled to follow the course of his thought - which has constantly undergone fresh modifications in various directions from the period when, as a pupil of Charcot's, he struck out on a new road down to the present. The first paper is a sympathetic obituary notice of Charcot, which at the same time reveals his own point of departure from the master's standpoint; the last is a new statement of "My Views on the Part played by Sexuality in the Etiology of the Neuroses." Charcot would have said it played no part, for he believed that the whole of the etiology was covered by heredity; but Freud is more than ever convinced that this is not the case, and he endeavours to set down as clearly as possible where he considers that sexuality intervenes as a factor, and in what direction his views have been modified by experience. Hysteria he still regards as "the expression of a special relationship of the individual's sexual function," and he still believes that childish experiences have an influence over the later direction of the patient's hysterical state, but he no longer speaks of early sexual experiences as "traumatic," and he recognises the part herein played by hysterical imagination; "infantile sexual trauma" gives place to "infantilism of sexuality." Along this line he has been brought somewhat nearer to Charcot's position and attaches primary importance to heredity and constitution, adding, however, that he thinks more of "sexual constitution" than of general neuropathic disposition. Masturbation he regards as a main cause of neurasthenia, and coitus interruptus as producing neurosis of anxiety.

This view certainly requires for its justification the emphasis on heredity, for minor sexual aberrations are far too common to be regarded as injurious to a constitution that is not aboriginally unsound.

While these studies are mainly concerned with neurasthenia and allied states, in one interesting passage (pp. 124 et seq.) Freud suggests that in some cases paranoia resembles hysteria and imperative ideas in that its symptoms may be determined by the suppression of painful memories of a sexual character dating from early life. A case is brought forward in which this could be clearly shown. This idea is suggestive, and it is probable that many readers, recalling cases of systematised delusion with which they were intimately acquainted, may bring to mind instances in which an ancient episode of sexual nature which the patient had, so far as possible, pushed out of consciousness, serves to form part of the basis of the later auditory hallucinations.

In an essay on psychotherapy the author discusses the origin and development of his method in its therapeutical aspects. The method appears to have been originally due to Breuer, who called it the "cathartic" method; Freud prefers to call it the "analytic" method. It is entirely distinct from hypnotism (which Freud has abandoned for over eight years), being indeed the exact opposite of hypnotism. By the hypnotic method it is sought to put something into the patient; by the cathartic or analytic method it is sought to take something out of him. Freud illustrates the difference by reference to Leonardo da Vinci's technical disctinction between the different ways of art, the via di porre, or the painter's way, of putting in something that before was not there, and the via di levare, or the sculptor's way, of removing something that is there.

Freud's style is always clear, attractive, and sincere, and this book is well worth the perusal of all who desire to become acquainted with the work of one of the subtlest and most original investigators in a difficult field.

HAVELOCK ELLIS

\section{REFERENCE}

Journal of Mental Science, January 1907, 172-173.

Researched by Henry Rollin, Emeritus Consultant Psychiatrist, Horton Hospital, Epsom, Surrey doi: $10.1192 /$ bjp.190.5.45। 